\title{
Research on the Development Model of Sichuan Minority Sports Towns in the Background of Accurate Poverty Alleviation*
}

\author{
Tianchao Yang \\ Southwest University for Nationalities \\ Chengdu, China 610065
}

\author{
Tian Liu \\ Southwest University for Nationalities \\ Chengdu, China 610065
}

\author{
Liang Zhai** \\ Sichuan Agricultural University \\ Ya'an, China 625014 \\ *** Corresponding Author
}

\begin{abstract}
More and more attention has been paid to the construction of towns with sports characteristics. The traditional ethnic sports in Sichuan Ethnic Minority Areas contain great cultural value and economic potential. At present, the reasons of people's understanding and input, in the development and utilization of sports towns, few people study systematically the construction of national traditional sports towns in the minority areas of China's minority areas in the process of development and utilization of sports towns with sports characteristics. This paper intends to study the development path of sports characteristic towns in Sichuan ethnic minority areas, in order to provide theoretical support and decision-making reference for the development of innovative sports characteristic towns.
\end{abstract}

Keywords-Sichuan ethnic regions; town with sports characteristics; development model

\section{INTRODUCTION}

The Notice of the Ministry of Housing and Construction, the National Development and Reform Commission and the Ministry of Finance on Carrying out the Work of Fostering Special Towns in July 2016 is proposed in the Notice of the Ministry of Housing and Construction, the National Development and Reform Commission and the Ministry of Finance, "By 2020, our country will cultivate 1,000 unique and vibrant leisure tourism, business and trade logistics, modern manufacturing, educational technology, traditional culture, beautiful and livable towns and other characteristics." This programmatic document has quickly inspired enthusiasm for the construction of small towns with distinctive features throughout the country. As one of the

*This paper is supported by the Fundamental Research Funds for the Central Universities, Southwest University for Nationalities (2018SQN26).

2018 Teaching Research and Reform Project of Southwest University for Nationalities: "Research on the construction of practical training base for social sports majors in Ethnic Universities under the new situation" (2018YB24). characteristic towns, the sports characteristic towns play an important role in promoting the integration of sports and industrial innovation, coordinating the urban and rural dual development, and changing the malpractice of the traditional urbanization model, etc.

\section{DEVELOPMENT STATUS OF TOWNS WITH SPORTS CHARACTERISTICS AT HOME AND ABROAD}

The developed and mature sports towns abroad not only have the superior living environment, the profound historical and cultural relics and the distinctive city style, but also many famous universities and the headquarters of the world famous enterprises, which concentrate many resources which are incomparable in the big cities. Such as the headquarters of Global Sporting Goods Co., Germany - Herzogen Jerah, is the headquarters of three global enterprises Adidas, Puma, Schaeffler. There are also many Swiss ski towns such as Davos, which is not only home to the World Economic Forum, but also "the largest alpine ski resort in Europe". Davos is Europe's "paradise on earth" and one of Europe's largest top ski resorts. During the skiing season, more than 700000 tourists come here on holiday.

The construction of our sports towns is just beginning. In the construction of characteristic towns in Zhejiang Province, Jiangsu Province, and other places, fitness and leisure sports characteristics of the small towns have emerged in various places. Take Deqing Mogan Mountain Sports Town in Zhejiang Province as an example: At present, there are more than 70 sports enterprises in Deqing, In 2014, the sports industry made over 10 billion yuan in sales, and the investment in sports industry projects amounted to 1.26 billion yuan, mainly in the sale and manufacture of sports fitness, leisure, stadium services and sporting goods. 


\section{CHARACTERISTICS OF SPORTS RESOURCES IN SICHUAN REGION OF CHINA}

Sichuan Province has the largest number of world natural and cultural heritage and national key scenic and historic areas, with 7 world natural and cultural heritages, 15 national scenic areas, 25 national forest parks and 8 national geoparks. Most of these tourism resources are in the minority areas of Sichuan. Tourism resources in the minority areas of Sichuan have become the important support of Sichuan tourism and the important advantage and leading industry to promote the new economic growth point of Sichuan ethnic regions.

Sichuan's ethnic minority areas are rich in sports tourism resources and have a high concentration of poor people. They are still far from the economic level of Sichuan Province and even the whole country, and the income gap of residents is still large. To help the poor by developing sports tourism has become an important path to develop the economy of the western minority areas, and the development and construction of the sports towns with special characteristics is one of the important choices for the development of sports tourism. In terms of traditional Tibetan sports, the Tibetan, Yi and Miao ethnic minorities are rich in sports, It is these national sports projects that come from production and life, have regional characteristics and display individual characteristics, which lay a solid foundation for the development of sports towns in Sichuan ethnic areas.

\section{ANALYSIS OF DEVELOPMENT PATH OF SPORTS CHARACTERISTIC TOWNS IN SICHUAN ETHNIC MINORITY AREAS}

The realization of the goal of helping the poor in the construction of sports towns depends on the production of the sustainable profits of the projects. Only when the relevant industries, such as sports tourism, are developed and the project can produce sustainable profits, can the employment problem of the local residents be solved and the poverty problem be solved fundamentally.

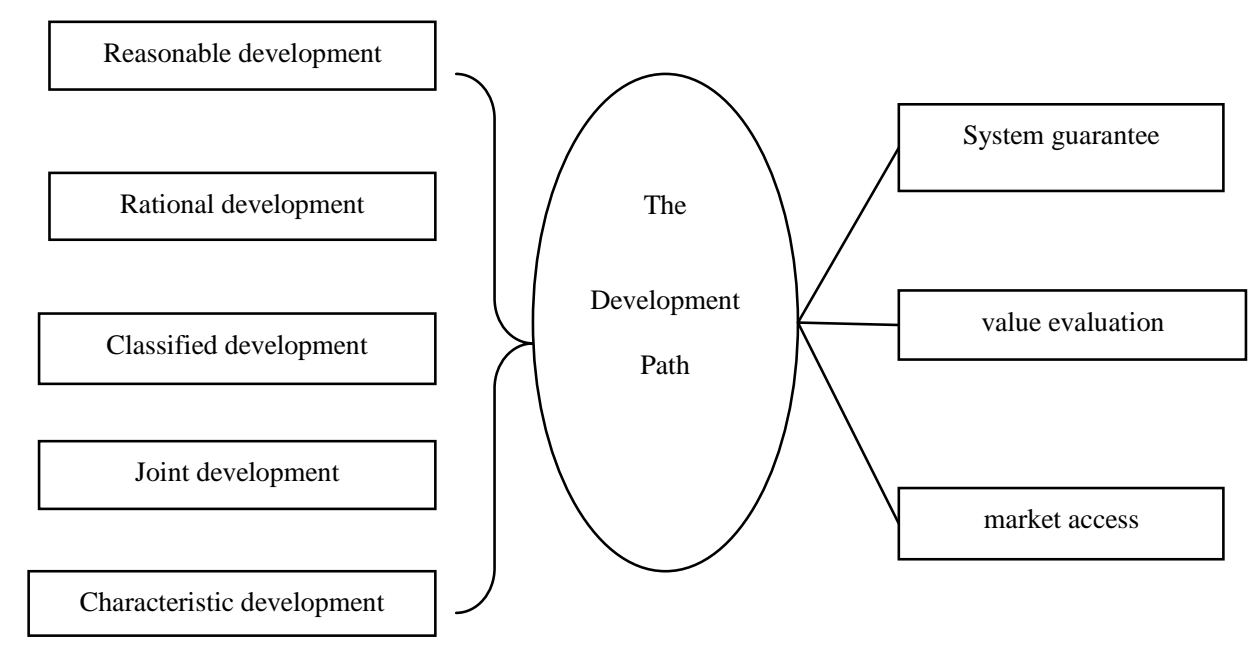

Fig. 1. The development path of sports characteristic towns in sichuan ethnic minority areas.

First, the rational development of sports towns in Sichuan ethnic minority areas needs to formulate scientific and comprehensive development strategies. The determination of development strategy should be carried out in combination of various aspects: from the perspective of natural resources and humane environment protection, rational development should be carried out, and the negative effects of development should be minimized; from the point of view of characteristic and differentiation construction, we should do classified development according to local conditions. From the perspective of multi-agent development mode, the rights and responsibilities of each subject need to be clarified before joint development. From the angle of sustainable development in the later period, we should excavate the characteristics according to the idea of innovation and development, and open up the industry space with characteristic.
Secondly, from the aspects of system guarantee path, value evaluation path and market access path, this paper gives policy recommendations on the construction of sports towns with characteristics in Sichuan ethnic minority areas. Among them, the way of system guarantee is mainly from the angle of legislation and the angle of the relevant policies of the government to the construction of the sports characteristic towns in the minority areas; The path of value assessment is to provide effective tools and methods to evaluate the value of the towns with sports characteristics in ethnic areas, and to make it feasible. The path of market access mainly means that the country should enlarge the scope of marketization of sports in the minority areas and make the market rules fully act on the development of the small sports town, In order to achieve the survival of the fittest and the survival of the fittest, the town with sports characteristics in the national areas will play a significant role in the development of the sports industry. 


\section{CONCLUSION}

Under the background of the 13th Five-Year Plan, the Party and the state attach more and more importance to the development of sports industry, especially the development of traditional sports in minority areas. As a Major Province inhabited by Minority Nationalities, it is very necessary to study the development of the traditional national sports characteristic towns in Sichuan Province in the light of the actual situation of the minority areas.

\section{REFERENCES}

[1] Jiang Qing, Jing Yan. Development of Sports Characteristic Towns in the Global Tourism Perspective. Open Report, 2017.10.

[2] Li Jun-jie, Chen Hao-hao. The Restrictive Factors and Basic Thinking of Poverty Alleviation and Development in Minority Areas. Journal of Zhongnan University for Nationalities (Humanities and Social Sciences Edition), 2015.6.

[3] Si Liang, Wang Wei. Theoretical framework and practical path of space production in China's sports towns.Journal of Shenyang Institute of Physical Education, 2017.10.

[4] Wang Xianyi, Zhai Fengzhou. How to Promote Sustainable Development of Rural Sports in Gannan? Asian Agricultural Research, 2017(07).

[5] Ashley C, Roe D,Goodwin H. Pro-poor Tourism Strategies:Making Tourism Work for the Poor: A Review of Experience. London: ODI,IIED, CRT, 2001: 22-23. 